\title{
Relações raciais na telenovela "Duas Caras": Evilásio e Júlia: um romance inter-racial
}

\section{Danúbia Andrade}

\section{Resumo:}

O artigo pretende analisar uma das possibilidades de representação dos conflitos raciais na telenovela Duas caras (TV Globo, 21 horas, 2007-2008). O foco estará em um dos romances que ancora a trama, o amor inter-racial dos protagonistas Evilásio e Júlia. Por meio do discurso teledramatúrgico, investigaremos os processos de representação da identidade negra brasileira. Nossas principais referências são Muniz Sodré, Kabengele Munanga, Frantz Fanon e Homi Bhabha.

\section{Palavras Chave:}

Telenovela brasileira; negritude, representação midiática

\section{Abstract:}

The article will attempt to analyze the possibilities of representation of racial conflicts in a specific Brazilian telenovela called Duas caras (TV Globo, 21h, 2007-2008). The focus will be on the interracial love affair involving the main characters, Evilásio and Julia. Throughout the telenovela discourse we will attempt to investigate the process of Black-Brazilian identity representation. The main resources are the writings of Muniz Sodré, Kabengele Munanga, Frantz Fanon and Homi Bhabha.

\section{Keywords:}

Brazilian telenovela, black identity, media representation

\section{Relacionamentos inter-raciais na telenovela brasileira}

As relações raciais tiveram destaque na telenovela Duas caras, de Aguinaldo Silva, exibida pela TV Globo, às 21 horas, nos anos 2007 e 2008. Neste artigo, buscaremos investigar uma das formas de representação da identidade negra brasileira por meio da análise do discurso teleficcional. O foco estará em um dos romances que ancora a trama, o amor inter-racial dos personagens principais Evilásio (Lázaro Ramos) e Júlia (Débora Falabella).

Dentre os 13 relacionamentos inter-raciais presentes nesta teleficção, escolhemos este, pois envolve o primeiro protagonista negro em telenovela global e, desta forma, desloca as questões pertinentes à negritude para o primeiro plano.

Ao longo do estudo, pretendemos expor algumas cenas nas quais o discurso da segregação racial e de aspectos específicos da identidade negra ganharam dimensões palpáveis e passaram a configurar conflitos teledramatúrgicos. Acreditamos que a forma de abordagem destas temáticas na teleficção seja capaz de auxiliar o entendimento das (in)visibilidades de tais mecanismos na esfera do real, conduzindo o olhar do negro sobre Si e sobre o Outro. Buscaremos compreender para além das estruturas visíveis, uma vez que a 
produção social de sentido se esconde nas entrelinhas discursivas.

Compreendemos que a telenovela brasileira, por sua penetração e abrangência no cotidiano do telespectador, tem a capacidade de interferir ativamente nos modos de construção de sentido no que se refere às identidades pessoais e coletivas. Isto se dá porque a ficção seriada fornece dados para a aferição da realidade social, integrando os indivíduos, ditando regras comportamentais e, portanto, atuando diretamente na conformação do sentimento de pertencimento a um grupo racial. Nos termos de Aluizio Trinta,

Os meios de comunicação, em cujo concerto avulta a televisão (e, entre seus programas, a telenovela), compõem relevantes contextos, em cujo interior indivíduos, grupos e comunidades elaboram, propõem, celebram, negociam e defendem suas identidades, tomando por base seu autoconceito e a sua autocompreensão, componentes basilares. (TRINTA, 2007: 152)

Os aspectos que ampliam na telenovela este potencial de penetração na domesticidade do espectador, provocando muitas vezes laços fortes de afetividade que interferem sobremaneira na formação identitária, dizem respeito ao seu formato seriado coligado ao tempo da vida cotidiana e a sua capacidade de narrativização da sociedade. Recorrendo a Milly Buonanno (2002: 76; 2004: 339), precisamos levar a sério as histórias, e especialmente aquelas transmitidas pela televisão, pois é por meio delas que a sociedade se representa. A telenovela nos fala e, ao mesmo tempo, fala de nós. Poderíamos dizer que a sociedade constrói e é construída nas tramas da teleficção.

Assim sendo, as formas de representação das relações amorosas entre um homem negro e uma mulher branca dizem muito além da simplicidade melodramática que se espera de um produto dito superficial como a telenovela. No interior desta narrativa, aparentemente despretensiosa, há uma compreensão das relações raciais no Brasil que se expande do ficcional e conduz os públicos a uma noção específica de realidade social.

\section{Um Romeu e Julieta a Aguinaldo Silva}

Antes mesmo de apresentar os personagens envolvidos neste enredo shakespeariano, adianto sem suspense que eles terminam juntos, casam-se no capítulo final em cerimônia católica e que têm um filho como símbolo do happy end. A história não se desenrolou necessariamente nesta ordem, mas em muito pouco o amor de Júlia e Evilásio diferencia-se daqueles que estamos acostumados a ver nas tramas melodramáticas.

De fato, o casal se conhece, apaixona-se de pronto e passa a enfrentar dificuldades até os últimos suspiros da telenovela, no qual se dá o desfecho tão esperado e reconfortante. O que nos chama a atenção neste par romântico, entretanto, é justamente a adversidade maior que os separa: o preconceito racial da família da moça. Cabe-nos apresentar, enfim, nosso Romeu e nossa Julieta.

Evilásio Caó é um jovem de 27 anos, nascido e criado em uma comunidade carente do subúrbio carioca. É o braço direito de Juvenal Antena (Antônio Fagundes), seu padrinho, na Associação de Moradores e Amigos da Favela da Portelinha (AMAP), onde exerce todos os tipos de função, de secretário à segurança. Corajoso, fiel, inteligente e solidário, Evilásio seria um dos poucos personagens complexos de Duas caras sem duas caras.

A idéia que quis passar com o título Duas caras é a de que as pessoas estão sempre em mutação, embora não percebam este processo. O Evilásio iniciou a trama como um menino ingênuo e cresceu adorando o seu padrinho Juvenal. Só depois é que passou a discordar do líder da 
Portelinha e deu um grito de liberdade: a virada do personagem. Agora sobre ele ser correto, o herói da trama, quis fazê-lo assim mesmo. Escrevi alguns - poucos - personagens sem este "lado B” como o Evilásio, a mãe Setembrina e o Pastor Lisboa. (SILVA, 2008: s/p)

O sobrenome traz consigo a referência à lei brasileira que combate o preconceito racial: a Lei Caó, $\mathrm{N}^{\circ}$ 7.437. Instituída em 20 de dezembro de 1985, ela define a prática do racismo como crime inafiançável. Seu autor foi o ex-jornalista Carlos Alberto de Oliveira Caó. O viés político do personagem desenvolvese no decorrer da telenovela, culminando com sua eleição para vereador no Rio de Janeiro. Inicialmente, um pau mandado de Juvenal Antena, em seguida, um sujeito crítico, confiante no discurso democrático e na força da união popular.

No campo sentimental, Evilásio envolve-se com duas mulheres ao longo da história: a madura Guigui (Marília Gabriela) e a jovem Júlia. As duas são brancas, inteligentes e intelectualizadas, além de representantes das elites paulistana e carioca. Júlia é a caçula dos Queiroz Barreto, família de advogados da alta sociedade. Estudou cinema e atua como produtora de um documentário. Sua atividade profissional a levará a um mundo até então desconhecido, a favela da Portelinha, onde conhecerá o homem que mudará sua vida e a de sua família.

Na Sinopse de Duas caras, Aguinaldo Silva já desenhava os contornos deste romance:

Ele [Evilásio] está fadado ao casamento com uma das muitas mocinhas da comunidade que o assediam... Até o dia em que chega lá uma equipe de filmagens para fazer um documentário sob a direção do promissor cineasta Duda Monteiro, ele conhece uma de suas assistentes, de nome Júlia, se encanta por ela e logo descobre que este sentimento é recíproco. Temos aqui uma situação clássica, a de Romeu e Julieta (...). E um Romeu e Julieta com algumas complicações mais incontornáveis que a desavença familiar da história original, pois no nosso caso Evilásio é negro, favelado e de poucas letras e Júlia, branca, muitíssimo bem educada e nascida numa família de nome e muitas posses. (SILVA, 2007: 71)

Nos momentos seguintes desta análise, apresentaremos duas circunstâncias específicas nas quais o racismo foi colocado em cena, o primeiro encontro de Evilásio e Júlia, que se passa na Portelinha, e o jantar oferecido na cobertura dos Barreto, no qual ofensas racistas foram servidas como prato principal.

\section{Primeiros olhares}

Como dissemos, ao representar os conflitos raciais, a telenovela brasileira rascunha uma versão de mundo concreto, sinalizando quais problemáticas tocam a negritude e como elas se encontram no dia-a-dia. Em outros termos, a ficção seriada oferece modelos de realidade que colaboram para a noção do real criada pelo telespectador.

Neste sentido, a cena em que Júlia encontra Evilásio pela primeira vez, exibida em 11 de outubro de 2007, toca em pontos nevrálgicos do preconceito racial brasileiro e aponta perspectivas interessantes para a discussão. Isto porque, neste contato, a jovem branca irá confundir o rapaz negro com um assaltante e terá medo do que representa a sua negritude, medo de seu corpo negro.

O pensamento de Júlia reproduz um temor socialmente reconhecido, mas que deve ser avaliado além da esfera da naturalidade. Afinal, há que se interrogar por que o indivíduo negro tem seu corpo atrelado a uma pré-concepção de marginalidade. E, ainda, por que a negritude é lida, num primeiro momento, como sinônimo de perigo social. 
Devemos compreender que quaisquer identidades são produtos em construção, derivadas de processos contínuos de ressignificação de sentidos que passam, necessariamente, por relações de poder. Mas em que momentos deste processo atrelaram-se valores negativos à identidade negra? E se em todo processo de ressignificação identitária há relações de poder, quais os fins da negativização dos negros aos olhos da sociedade?

Para Bhabha (2005: 105), a desumanização da imagem do negro é parte de uma estratégia de dominação do branco colonizador que pretendia solucionar a contradição entre os ideais de liberdade e uma economia fundada na escravidão. Negando a humanidade dos povos negros legitimou-se a atividade econômica mais lucrativa naquele momento histórico. O discurso colonial dependia inteiramente do conceito de fixidez na construção ideológica da alteridade. E o estereótipo foi utilizado como estratégia discursiva que exclui o Outro e combate a insegurança diante do estranho. "O objetivo do discurso colonial é apresentar o colonizado como uma população de tipos degenerados com base na origem racial de modo a justificar a conquista e estabelecer sistemas de administração e instrução.” (BHABHA, 2005: 111)

Como nos lembra Kabengele Munanga (2006: 28), um grupo pode sofrer uma deformação real se as pessoas ou sociedades que o rodeiam lhe devolvem uma imagem limitada, depreciativa ou desprezível deles mesmos. O reconhecimento inadequado ou a invisibilidade social podem acarretar opressão e aprisionamento. No caso dos negros, durante gerações a sociedade branca construiu e impôs uma imagem depreciativa, enxergando-os como incivilizados e inferiores. A falta de reconhecimento infligiu "uma ferida cruel ao oprimir suas vítimas de um ódio de si paralisante" (id.).

Em suas análises, Frantz Fanon $(1983 ; 2005)$ explicita que o complexo de inferioridade que acompanha o negro surge após um processo duplo: inicialmente, econômico, em seguida, pela epidermização(1) dessa inferioridade. Submerso em uma cultura que trabalha para a manutenção deste complexo, em uma sociedade que afirma a superioridade de uma raça, o negro sobrevive no anseio de se tornar branco, embranquecer. Para tanto, são requisitos a negação de suas origens, expressões culturais e religiosidades. Neste trajeto de rejeição da negritude o indivíduo sofre de despersonalização. Esta decorre, em grande parte, do modo como seu corpo é aprisionado pelo olhar daqueles que o excluem.

Todos os esforços são feitos para levar o colonizado a confessar a inferioridade da sua cultura, transformada em condutas instintivas, a reconhecer a irrealidade da sua nação, e finalmente o caráter inorganizado e não acabado de sua própria estrutura biológica. (FANON, 2005: 271)

Voltando à Duas caras, na cena em que Júlia conhece Evilásio, observamos não só o encontro de dois personagens, ou o ponto inicial de um romance, mas também o choque de dois mundos.

Sem nunca ter pisado em uma favela, Júlia vai à Portelinha na expectativa de encontrar Juvenal Antena, a quem intercederia em nome da produção do documentário sobre a favela-modelo. Em sua chegada, tem um imprevisto: um dos pneus de seu carro fura. É noite e ela está sozinha em uma rua estreita e mal iluminada. A jovem sai do automóvel, apanha os equipamentos e desajeitadamente prepara-se para trocar o pneu. Enquanto isso, Evilásio a observa de longe, sem ser visto.

Importante destacar que enquanto Júlia está entretida com a troca do pneu do carro, passa muito próximo a ela uma outra personagem moradora da favela, o traficante Ronildo (Rodrigo Hilbert). No entanto, ao contrário da imagem de Evilásio, a proximidade com Ronildo não desperta nenhuma aflição na jovem, pois o bandido tem aspecto "confiável”; ele é branco, tem cabelos loiros e olhos azuis.

Ao sair do beco de onde espreitava, deixando-se visível, Evilásio coloca um objeto na cintura que Júlia 
pensa ser um revólver. O desconhecido "armado" caminha em sua direção e ela corre apavorada para dentro do carro e tranca as portas e os vidros. Evilásio bate na janela e ela se assusta ainda mais. "Minha carteira tá vazia! Vai embora!" Indignado, o rapaz esmurra o vidro. "Meu carro é blindado, vai embora!". Diante disso, ele apanha uma pedra e passa em frente ao pára-brisa. Júlia grita: "Ai, meu Deus! Ele vai quebrar o vidro!". Mas a pedra é usada apenas para escorar o veículo enquanto troca o pneu. Trabalho executado, Evilásio para ao lado da janela, simula limpar as mãos e mostra o celular preso a sua cintura. Júlia permanece dentro do automóvel atordoada.

Na seqüência, que foi ao ar no dia 12 de outubro de 2007, Júlia vai atrás de Evilásio para desculpar-se por tê-lo confundido com um ladrão. O cenário ainda é uma das ruas da Portelinha, mas desta vez Evilásio está acompanhado por outros funcionários da AMAP. O diálogo é tenso. Ela posiciona-se de forma humilde com sincero constrangimento. Ele, por seu turno, não disfarça sua indignação e utiliza a ironia para agredi-la.

Evilásio:_Se tá querendo comprar alguma coisa, errou de favela.

Júlia: _Não, não é nada disso. Primeiro, eu vim aqui para te pedir desculpas. Desculpa mesmo pelo meu comportamento. É que você saiu do nada, de repente, e eu levei o maior susto. Eu fui uma burra... Eu não notei que você estava querendo só me ajudar. Desculpa.

Evilásio:_Quem falou? Eu estava querendo era te assaltar mesmo. Só que eu cheguei junto, achei meio caído e mudei de idéia. Achei melhor te ajudar.

Júlia _ Você não pode tá falando...

Evilásio interrompendo:_Sério? Claro que eu tô falando sério. O que mais um cara da favela como eu podia querer com uma princesinha do asfalto como você a não ser assaltar e matar? Aliás, se eu fosse você não ficava aqui dando mole não, porque eu posso mudar de idéia e partir pra cima de novo.

Júlia:_Aqui, você tem toda razão de ficar chateado, eu fui uma preconceituosa. Me desculpa. Mas sabe o que é, esse mundo tá tão louco... Você tem que entender também...

Evilásio interrompendo novamente:_Pelo amor de Deus, eu não tenho que entender nada. Aliás, eu não tô nem aí pro que você pensa a meu respeito. Eu devia te processar, sabia? Lei Afonso Arinos, já ouviu falar? Fazer você sentir onde dói pra gente do teu tipo que é no bolso! Ah, quer saber, eu não tô nem afim de perder mais um segundo do meu tempo com você!

Júlia:_Espera! Só um minuto. Você trocou o pneu do meu carro, você foi super legal... deixa eu pelo menos te pagar uma cervejinha...

Júlia tira notas de dinheiro e as oferece para Evilásio.

Evilásio:_Sabe o que você faz com essa tua cervejinha?

Mestre(2) grita: _Evilásio!

Evilásio entra no carro e sai.

No diálogo transcrito, observamos as impressões resultantes deste primeiro contato. De ambos os lados 
houve processos de estigmatização, pois se para Júlia um homem negro em uma rua mal iluminada dentro de uma favela era a tradução de "perigo", para Evilásio uma jovem branca só entraria em uma comunidade carente à noite em busca de drogas.

No pedido de desculpas da moça, observamos uma reticente tentativa de justificar sua atitude preconceituosa seja pelo susto provocado, pela escuridão do local ou pela situação de violência na qual vivemos. Entretanto, há que se destacar que a presença de Ronildo neste mesmo cenário foi quase imperceptível tanto para a personagem, quanto para parte da audiência. Acima de qualquer justificativa, foi a presença de Evilásio, de seu corpo negro, que a assustou. Mais que uma situação embaraçosa, um mal-entendido, tratou-se de um fato racista.

Evilásio está ciente disso e não perdoa Júlia. Na fala "eu estava querendo era te assaltar mesmo" ele deixa claro que conhece o papel social estereotipado que freqüentemente o persegue. Afinal, "o que mais um cara da favela como eu podia querer com uma princesinha do asfalto como você a não ser assaltar e matar?". Evilásio tem consciência de que há um aprisionamento da identidade negra masculina no estigma do sujeito marginal e violento. Um jovem negro morador de periferia não pode ser nada mais do que aquilo que está determinado socialmente. É natural que ele seja um bandido e que, portanto, não queira ajudar a desconhecida e, sim, fazer-lhe algum mal. A intenção de Júlia de retribuir financeiramente ofende na medida em que instaura outro axioma, o de que ele só pretendia ajudá-la para ganhar algo em troca.

Apesar das impressões negativas do primeiro encontro, Evilásio e Júlia tornam-se amigos e a jovem o convida para um jantar em seu luxuoso apartamento, como veremos adiante.

\section{O discurso racista na mesa do jantar}

Esta cena, exibida nos dias 24 e 25 de outubro de 2007, pode ser considerada a mais interessante no que diz respeito ao tratamento do racismo ao longo de Duas caras, pois explicita preconceitos raciais encobertos socialmente que poucas vezes entraram em debate na esfera midiática. No contexto, um jantar oferecido pela família Barreto em seu apartamento em que Evilásio é o único convidado negro.

Já nos primeiros momentos da ficção, os conflitos raciais ganham corpo. Gioconda (Marília Pêra), a matriarca dos Barreto, confunde Evilásio com um entregador. Apesar de estar arrumado corretamente para o evento, o rapaz é confundido com um empregado unicamente por ser negro. O que nos remete à perspectiva de Frantz Fanon $(1983 ;$ 2005) de que o negro é perseguido por sua negritude. Em outros termos, ainda que se vista e se porte contrariando os estigmas e estereótipos de inferioridade e subalternidade que cercam a negritude, o sujeito negro sempre será revestido dos valores negativos da "raça" pelos olhares do Outro (e muitas vezes de si mesmo). O negro é sobredeterminado exteriormente. Seu estigma é prontamente apreendido. "Como a cor é o sinal exterior mais visível da raça, ela tornou-se o critério através do qual homens são julgados sem se levar em conta sua educação e seu nível social." (FANON, 1983: 97)

Na seqüência, Barreto esforça-se para parecer gentil com o convidado negro de sua filha, mas ficam claros o seu descontentamento e desconforto. O advogado oferece várias vezes uísque a Evilásio, na tentativa de embebedá-lo. Mas quem termina alcoolizado é o próprio Barreto, enquanto Evilásio permanece sóbrio e aparentemente à vontade entre os outros convidados. Um pouco antes de iniciar o jantar, Barreto observa nervoso a troca de olhares entre Júlia e Evilásio e podemos arriscar que este tenha sido o estopim da discussão que se seguirá.

Antes, porém, é preciso interrogar o porquê de Aguinaldo Silva apresentar o personagem racista em cena 
e, portanto, aquele responsável pela autoria das acusações preconceituosas, como bêbado. De que forma a não sobriedade de Barreto altera os contornos de seu discurso? Quais os limites transgredidos por ele que jamais o seriam caso estivesse sóbrio? É fato que as convenções sociais que silenciam o racismo e invisibilizam os mecanismos discriminatórios só poderiam ser rompidas e despertadas através da desordem dos sentidos?

Inicia-se o jantar. Todos sentados à mesa e mais uma vez Barreto enche o copo de Evilásio. Em seguida, o advogado pergunta ao jovem o que ele achou do vinho que acabara de degustar. Com esta indagação, Barreto abasteceu-se no senso comum de que os negros não têm níveis intelectual e cultural comparáveis aos brancos. Assim, o negro favelado não conseguiria responder muito a respeito da qualidade do vinho, dando razão aos seus preconceitos e servindo de piada para os demais convidados. Mas Evilásio surpreende a todos ao responder "Gosto de asfalto quente com charuto". Sim, ele havia lido em uma revista especializada em vinhos que um bom malbec tem este sabor específico. E completa: "Eu nunca comi asfalto quente, muito menos charuto, mas com certeza esse vinho tem esse gosto!" Ao surpreender a todos com um comentário bem-humorado e inteligente, Evilásio desperta o ódio até então recalcado e inicia-se a sessão de ofensas.

Interessante ressaltar que o "gosto de asfalto quente com charuto" não nasce de uma brincadeira qualquer do rapaz para sentir-se menos estranho naquela mesa de ricos e brancos e, sim, fruto de um interesse antigo embasado em leituras. De que maneira ler revistas sobre vinhos quebra com os estereótipos solidificados a respeito de um negro favelado? Se ele soubesse tudo sobre futebol, cerveja, samba ou pagode o estranhamento seria o mesmo? Certamente que não.

Qual seria, finalmente, a resposta de Barreto a um negro capaz de intrometer-se em sua família, fazer rir aos seus convidados e conversar sobre qualquer assunto? "Que crioulo metido a besta!" Nessa frase, observamos a necessidade de preservar os espaços, evitar o contato, suspender a mistura. Para Muniz Sodré (1999: 258), o racismo não deve ser entendido apenas sob a perspectiva da exclusão social, mas principalmente enquanto mecanismo civilizatório organizado pela sociedade ocidental cristã de rejeição existencial, em outras palavras, consciente e subconscientemente, alijamento da alteridade. Esta lógica exacerba-se precisamente no instante da aproximação, quando o Outro abandona o seu lugar e ameaça penetrar os espaços hegemônicos, rompendo as fronteiras da hierarquia territorial. Desse modo, o nojo racista decorre do deslocamento inadequado do negro, invasão de um ambiente que "não é o seu lugar". Sodré (1999: 261) exemplifica com a seguinte metáfora: "ele (o negro, o índio, etc.) está ali onde não deveria, assim como o suflê preparado por um grande cozinheiro, antes lindo no prato sobre a toalha da mesa, poderia inspirar nojo se colocado sobre o lençol da cama."

Em sua fala, ao pedir desculpas aos seus convidados pela presença de Evilásio, Barreto banha-se em um dos preconceitos mais recorrentes contra o negro, aquele que diz respeito a sua não-humanidade. Ao dizer "se é que isso é gente", o personagem refletirá um axioma que tem raiz no século XV, quando os primeiros relatos sobre a existência dos negros africanos foram escritos por navegadores europeus. "A idéia de gente sem cabeça ou com ela no peito, com chifres na testa, ou com um só olho, gente com rosto de cão faminto e coisas do gênero dominava os escritos ocidentais sobre a África nos séculos XV, XVI e XVII." (MUNANGA, 1988: 14).

A inferioridade congênita do indivíduo negro, ancorada cientificamente pelo clima dos trópicos, justificou a escravidão disfarçada de "missão civilizadora". De fato, Barreto reproduz um pensamento que tem bases muito consistentes em nossa sociedade, que dá conta de supostas diferenças biológicas entre as raças: o negro seria menos humano, na medida em que mais primitivo, ligado aos instintos, incapaz de racionalizar. Evilásio está preso a todos estes estigmas e sua tentativa de contrariá-los por meio de um 
discurso inteligente compromete o delicado equilíbrio do jantar.

Duas falas subseqüentes retêm a nossa atenção e dizem respeito ao silenciamento do racismo como prática no Brasil, naquilo que Couceiro de Lima (2007: s/p) assestou como o "preconceito de ter preconceito", que faz com que a exclusão do negro em nosso país tenha caracteres muito distintos de outras partes do mundo. A discriminação racial é tida como inexistente e, portanto, uma fala abertamente racista somente poderia ser justificada pela ausência de razão. Júlia pergunta ao pai "você enlouqueceu?". Barretinho (Dudu Azevedo), o irmão, também advogado e, por conseqüência, ciente das leis que condenam o racismo como prática inafiançável, questiona "Oh, pai, pelo amor de Deus, você não acha que está pegando pesado demais prum advogado, não?”. Cada uma a seu modo, as duas interrogações deixam no ar a perspectiva de que os pensamentos racistas podem existir e que devemos conviver com eles, mas que não devem ser explicitados socialmente, menos por razões de crença na igualdade de direitos e mais por questões legais.

A lei de combate ao racismo é retomada na fala do deputado Narciso Tellerman (Marcos Winter): "Racismo no Brasil é crime, Barreto, e você como advogado deveria saber mais do que ninguém." Apesar da lei ser citada, em nenhum momento Evilásio questiona se deve ou não utilizá-la. A possibilidade de denunciar Barreto não é sequer aventada.

"Eu só falo o que todo mundo pensa e não tem coragem de dizer. Eu não gosto dessa gente. É uma gente insolente, uma gente indolente que só serviu para atrasar esse país... Se o Brasil chegou até esse ponto em que está foi graças aos europeus... A culpa desse país não funcionar é toda dessa gente!"

Nesta fala, observamos o uso repetido dos termos "essa gente", nos quais o pronome demonstrativo sinaliza o não pertencimento ao grupo, bem como o tom de voz do discurso conota a palavra "gente" de puro desprezo. Este pensamento corrobora a perspectiva de pureza racial de parte da elite branca brasileira. Em um país que supervaloriza suas origens européias, a elite não sente pertencer ao conjunto dos descendentes africanos.

Para Barreto, o desenvolvimento do Brasil foi comprometido pela indolência dos negros. Tal máxima tem raiz no período escravagista e operava como uma das estruturas legitimadoras da escravidão.

O colonizador legitima seu privilégio pelo trabalho e justifica a nulidade do colonizado pelo ócio. No retrato constará uma inacreditável preguiça, ao contrário do colonizador, que tem um gosto virtuoso pela ação. Este último sugere que o trabalho do colonizado é pouco rentável, o que autoriza os salários insignificantes e a exploração. (MUNANGA, 1988: 22)

Ao dizer que a presença dos negros só serviu para atrasar o desenvolvimento do Brasil, Barreto dá vazão ao pensamento de muitos. Estes, membros ou não das elites, crêem piamente na incompetência congênita dos negros, em sua preguiça e pré-disposição para a malandragem, em contraponto com a vivacidade e inteligência dos brancos.

A interferência de Narciso em defesa de Evilásio também merece destaque, pois retoma uma prática corriqueira em telenovelas brasileiras que é dispor personagens brancas (3) para amparar e responder pelos negros quando em situação discriminatória. A isto Araújo (2008: s/p) chama "personificação do mito da Princesa Isabel". Neste sentido, embora Evilásio não saia de cena sem antes se pronunciar, é 'Narciso' quem fala sobre a importância dos negros na sociedade brasileira, é ele quem toca na 
criminalização do racismo e é ele também quem ressalta Evilásio em sua condição individual, como um homem digno de se casar com Júlia.

No que diz respeito à fala de Evilásio, sua defesa está em posicionar-se como imune a todas aquelas acusações e, ao mesmo tempo, desqualificá-las como "besteira" e "ignorância". Ainda que o rapaz considere o discurso de Barreto como uma inverdade que não o afeta, não há intenção de perdão ou de relevar as ofensas pelo fato do advogado estar bêbado. Sua postura é altiva, digna e definitiva.

A discussão do racismo na sociedade brasileira exposta nesta cena de forma bastante clara apresenta não somente uma crítica ao pensamento que condena os negros aos estigmas e estereótipos arregimentados no período colonial, bem como fortalece o debate sobre a temática ao trazê-la para o repertório cotidiano proporcionado pela ficção seriada. Neste sentido, as falas preconceituosas de Barreto expõem sentimentos geralmente encobertos socialmente, ainda que presentes no dia-a-dia e sensíveis aos negros e negras brasileiros.

\section{Em busca do happy end}

Ademais de abordar as formas de aparição do racismo em Duas caras, especialmente nas circunstâncias que envolveram o par romântico Júlia e Evilásio, cabe analisar como a autoria desta telenovela solucionou o conflito racista. Como sabemos, os plots teleficcionais prescindem de resolução para que o desfecho da trama ocorra.

Uma das circunstâncias que operou diretamente para que Barreto vencesse seus preconceitos raciais foi o nascimento de seu neto Misaelzinho e o fato deste personagem ter doado sangue para salvar a vida do bebê. Nascido de um parto com complicações, o nenê precisou trocar todo o sangue do corpo e apenas Barreto tinha compatibilidade.

Evilásio:_Doutor Barreto, é meu filho, é negro como eu e é seu neto...

Gioconda:_Barreto, não me venha com atitudes racistas agora, você vai salvar a vida do seu neto!

Barreto:_Mas é claro, Gioconda! Eu faço qualquer coisa para salvar o meu neto! Doutor, meu sangue é $\mathrm{AB}$ negativo.

Antes de sair de cena, em pensamento, Barreto elucubra, "Se todo sangue no nenê for o meu, será que ele vai ser branco como eu?"(4)

Barreto imagina que por meio da doação de sangue poderia "embranquecer" o neto e por isso aceita prontamente ajudar-lhe. Mais que salvar a vida de Misaelzinho, o advogado racista aventa a possibilidade de que uma vez com sua carga sangüínea circulando por todo o corpo, a criança herde imediatamente suas qualidades de branco. Desta maneira, a doação de sangue em Duas caras não significou a extirpação imediata do preconceito racial do personagem racista, ainda que o nascimento de um neto o tenha "amolecido".

Com efeito, o que arremata o racismo de Barreto é a resolução de um trauma familiar(5). Sua avó, cujas fotos e registros haviam sido cuidadosamente escondidos, teve um romance com um homem negro e abandonou a família para viver este relacionamento. Barreto, assim como o restante dos parentes, não aceitou tal fato e passou a comportar-se de forma discriminatória.

O racismo, dessa forma, não é encarado pelos produtores e autores de Duas caras como um problema 
social, coletivo, de ordem histórico-econômica e, sim, pessoal, individual, passível de justificativa. As questões que motivaram as atitudes racistas de Barreto não dizem respeito a uma longa história de dominação e exclusão social dos negros, desde a escravidão até os dias de hoje, mas toca em um conflito psicológico. A mágoa de perder a avó e ter de vê-la gerando filhos com um homem negro é o que fundamenta o racismo do poderoso advogado. Uma vez perdoada a avó, nada mais o impede de aceitar Evilásio.

Por fim, cabe destacar que o conflito racial, no que concerne a Júlia e Evilásio, fica limitado à esfera da realização amorosa, não ganhando destaque em outras circunstâncias da vida social como a ascensão profissional ou a aceitação de Misaelzinho. Assim, uma vez solucionado o preconceito racial de Barreto, o par romântico encontra a felicidade em definitivo e se estancam quaisquer feridas raciais. Duas caras rascunha um país em que o racismo só existe nas relações de afetividade e no qual o amor é a principal arma de combate ao preconceito.

\section{Bibliografia:}

ARAÚJO, Joel Zito. "Identidade racial e estereótipos sobre o negro na TV brasileira". In: Tirando a máscara. Ensaio sobre o racismo no Brasil. São Paulo: Paz e Terra, 2000, p.77-95.

. A negação do Brasil. O negro na telenovela brasileira. 2.ed. São Paulo: Senac, 2004.

. "A força de um desejo - a persistência da branquitude como padrão estético audiovisual". Revista USP. Racismo II. São Paulo, n.69, p. 72-79, março/maio. 2006.

O negro na mídia. Juiz de Fora, UFJF, Conferência de Abertura do II Colóquio de Culturas e Diásporas Africanas, realizado na UFJF, 3 a 6 de nov. 2008.

BHABHA, Homi. O local da cultura. Belo Horizonte: UFMG, 2005.

BUONANNO, Milly. El drama televisivo. Barcelona: Gedisa Editorial, 1999.

. "Conceptos clave para el story-telling televisivo. Calidad, mediación, ciudadanía". Diálogos de la Comunicación. n.64. Perú. 2002. Disponível: http://www.dialogosfelafacs.net/dialogos_epoca/pdf/6406MillyBuonanno.pdf Consultado em 11 fev 2008.

. "Além da proximidade cultural: não contra a identidade, mas a favor da alteridade". In.:

Telenovela. Internacionalização e interculturalidade. São Paulo: Loyola, 2004, p. 331-360.

COUCEIRO DE LIMA, Solange Martins. O negro na televisão de São Paulo: um estudo de relações raciais. São Paulo, FFLCH/USP, 1983.

. "Eu vi o Lázaro Ramos beijar a Marília Gabriela”. Revista Sesc TV, 2007. Disponível em

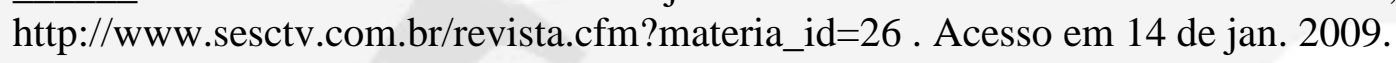

FANON, Frantz. Pele negra, máscaras brancas. Rio de Janeiro: Fator, 1983.

Os condenados da terra. Juiz de Fora: Ed. UFJF, 2005. 
MUNANGA, Kabengele. Negritude. Usos e sentidos. 2.ed. São Paulo: Ática, 1988.

. Rediscutindo a mestiçagem no Brasil. Identidade nacional versus identidade negra. Petrópolis: Vozes, 1999.

"Construção da identidade negra no contexto da globalização". In: Vozes (além) da África. Juiz de Fora: Ed. UFJF, 2006.

RUFINO DOS SANTOS, Joel. Zumbi. São Paulo: Moderna, 1985.

SILVA, Aguinaldo. Duas caras. Sinopse para uma novela das oito. Rio de Janeiro: [s.ed], 2007.

. Entrevista com Aguinaldo Silva sobre "Duas caras" . Rio de Janeiro: 2008. Entrevista concedida a Danubia Andrade em 4 ago. 2008.

SODRÉ, Muniz. Claros e escuros. Identidade, povo e mídia no Brasil. 2.ed. Petrópolis: Vozes, 1999.

TRINTA, Aluizio Ramos. "Identidade, identificação e projeção: telenovela e papéis sociais, no Brasil". In: Comunicação: tecnologia e identidade. Rio de Janeiro: Mauad X, 2007, p.151-164.

\section{Notas:}

(1) O termo "epidermização" é utilizado porque acrescenta sentidos à idéia de interiorização. Mais que um processo inconsciente, trata-se de algo que está irremediavelmente preso à imagem do negro. Sua fisionomia não lhe permite fugir à negativização da raça.

(2) Mestre é um dos funcionários da AMAP. Ele tem este apelido porque faz parte do grupo considerado um dos “anões” de 'Juvenal Antena', em referência aos sete anões do conto infantil.

(3) O personagem Narciso Tellerman é considerado como branco, independente de seu sangue judeu, acompanhando as disposições raciais presentes na sociedade brasileira, na qual a diferenciação entre judeus e brancos ganha contornos extremamente sutis.

(4) Diálogo exibido no dia 12 de fevereiro de 2008.

(5) Cena levada ao ar dia 23 de maio de 2008.

\section{Mini Currículo :}

Danubia Andrade é jornalista mestre em Comunicação Social pela Universidade Federal de Juiz de Fora (UFJF). Dentre suas mais importantes publicações, destaca-se a organização do livro "Culturas e Diásporas Africanas" (Ed. UFJF, 2009). Atualmente, é professora do Departamento de Rádio e TV da Facom / UFJF. 